\title{
Partial Substitution of Chromate by Borate for Cooling Water Inhibition
}

\author{
Aruna BAHADUR \\ National Metallurgical Laboratory, Jamshedpur 831007, India. E-mail: aruna@csnml.ren.nic.in \\ (Received on November 4, 1997; accepted in final form on January 16, 1998)
}

\begin{abstract}
Chromate is an effective and versatile inhibitor for industrial cooling water systems. Due to its toxicity, borate is added systematically to substitute chromate from 100 to $1 \%$ and tested as inhibitor for a mild steel, using radioactive tracer technique.

The amount of chromium in the film thickness of the inhibitor formed on the specimens is found to increase as borate concentration is increased up to $40 \%$ and decreases thereafter. The protection is obtained at $303 \mathrm{~K}$ at least up to $6 \mathrm{~h}$. By reducing chromate from 100 to $60 \%$, the $\mathrm{Cr}$ content in the protective film is found to double in $2-4 \mathrm{~h}$, which shows the synergistic effect of the inhibitor formulation as compared to that of chromate alone.
\end{abstract}

KEY WORDS: aqueous inhibitor; radiotracer technique; chromate; borate; synergistic effect.

\section{Introduction}

Chromate has been an important corrosion inhibitor for industrial water cooling systems since the sixties. It is a very effective and versatile passivator at relatively high levels and protects a variety of metals and alloys in the presence of halide ions in aqueous medium. ${ }^{1,2)}$ However, apart from being expensive, its usage has certain limitations. Chromate used below a certain critical concentration leads to acceleration of pitting. The pit initiation is rapid at the critical level but later the pits propagate slowly. ${ }^{3}$ Secondly, chromate sometimes gets reduced to insoluble chromic salts and thus becomes ineffective and uneconomical as an inhibitor. The most important constraint in the use of chromate is its toxicity and attendant disposal problem, in view of the increasingly critical demand on environmental protection. Effluents containing appreciable quantities of chromate $\left(\mathrm{Cr}^{6+}\right.$ should be $<0.05 \mathrm{mg} / /$ in blowdown ${ }^{4)}$ ) cannot be discharged into streams or other waterways. The environmental problem can be solved either by effluent disposal treatment, which is expensive, or by developing inhibitor formulations having lower concentrations of chromate. The latter entails use of supplementary inhibitors, some of which may also reduce the undesirable localized attack (pitting) due to chromates. Also, the mixture of inhibitors being synergistic is expected to provide better inhibition than either alone. Various substitutes have been tried by researchers as follows:

Zinc provides ready protection which is not very durable. Zinc used in conjunction with chromate (1-5 ppm) provides good protection at low levels $(5-10 \mathrm{mg} / \mathrm{l})$ in the presence of $\mathrm{Cl}^{-}$and $\mathrm{SO}_{4}^{2-}$ ions along with fouling control. ${ }^{5-7)}$
However, zinc becomes ineffective when $\mathrm{SO}_{4}^{2-}$ content in water increases and both being toxic require blowdown treatment. Zinc has been used along with phosphate effectively for steel in $\mathrm{pH}$ range from 7.8 to $8.0{ }^{8)}$ Nitrite in low concentration is effective in low flow conditions in cooling water. It is used generally in large quantities which is uneconomical. It also causes susceptibility to aerobic bacterial degradation and leads to oxidation to nitrate in open cooling systems. ${ }^{9}$ )

Non-oxidizing inhibitors like phosphate, molybdate, tungstate, silicate, benzoate etc. function in neutral and alkaline solutions and require oxygen for effective inhibition. Polyphosphate (PP) combined with chromate in the ratio of $2: 1$ is an effective inhibitor for many ferrous and non-ferrous alloys in narrow $\mathrm{pH}$ range from 6.0 to $6.5 .{ }^{10)}$ The PP, however, gets easily hydrated to form scale and causes microbic fouling. Orthophosphate addition to the PP inhibitor improves overall inhibition. ${ }^{10)}$ Molybedenum has been used to protect metals under diverse water conditions since 1930's either alone or along with nitrate and other agents. ${ }^{11-13)}$ Molybdenum is weekly held and is readily released by perturbation in electrode conditions. Silicate is used generally for protecting pipes in hot water systems. ${ }^{14)}$ Benzoate is effective in large quantities and requires $\mathrm{pH}$ control. ${ }^{15}$ ) The reduceable inhibitors $\mathrm{XO}_{4}^{n-}$ anions (e.g. $\mathrm{TcO}_{4}^{2-}$, $\mathrm{MnO}_{4}^{2-}, \mathrm{WO}_{4}^{2-}$ ) shift the anodic curve in the noble direction. Then either its own cathodic current may be sufficient to induce passivation or oxygen/other oxidizing agent can cause passivation. ${ }^{16)}$ The two distinct functions of inhibitor explain why a combination of two inhibitors is generally more efficient than either alone. In the present studies, borate is used to systematically replace chromate from 100 to $1 \%$ at room temperature in aqueous solu- 
Table 1. Compositions of experimental solutions. (Total $=40 \mathrm{cc}$, dilute active chromate soln. $=15 \mathrm{cc}$ )

\begin{tabular}{|c|c|c|c|c|c|}
\hline $\begin{array}{l}\text { Chromate: Borate } \\
\text { (By wt.) }\end{array}$ & $\begin{array}{c}\text { Chromate: Borate } \\
\text { (ppm) }\end{array}$ & $\begin{array}{c}\text { Total } \mathrm{Na}_{2} \mathrm{CrO}_{4} \\
(\mathrm{mg} / 40 \mathrm{cc})\end{array}$ & $\begin{array}{l}\text { Inactive chromate } \\
{\left[\begin{array}{c}\text { Total- } \\
0.0666(\mathrm{mg})\end{array}\right]}\end{array}$ & $\begin{array}{l}\text { Inactive chromate } \\
{\left[\begin{array}{c}0.2 \% \mathrm{Na}_{2} \mathrm{CrO}_{4} \\
\text { soln. (cc) }\end{array}\right]}\end{array}$ & $\begin{array}{c}\text { Borate } \\
0.1 \% \mathrm{H}_{3} \mathrm{BO}_{3} \\
\text { soln. }(\mathrm{cc})\end{array}$ \\
\hline $90: 10$ & $450: 50$ & 18.0 & 17.9334 & 8.967 & 2.0 \\
\hline $80: 20$ & $400: 100$ & 16.0 & 15.9334 & 7.967 & 4.0 \\
\hline $70: 30$ & $350: 150$ & 14.0 & 13.9334 & 6.967 & 6.0 \\
\hline $60: 40$ & $300: 200$ & 12.0 & 11.9334 & 5.967 & 8.0 \\
\hline $50: 50$ & $250: 250$ & 10.0 & 9.9334 & 4.967 & 10.0 \\
\hline $40: 60$ & $200: 300$ & 8.0 & 7.9334 & 3.967 & 12.0 \\
\hline $30: 70$ & $150: 350$ & 6.0 & 5.9334 & 2.967 & 14.0 \\
\hline $20: 80$ & $100: 400$ & 4.0 & 3.9334 & 1.967 & 16.0 \\
\hline $10: 90$ & $50: 450$ & 2.0 & 1.9334 & 0.967 & 18.0 \\
\hline $5: 95$ & $25: 475$ & 1.0 & 0.9334 & 0.467 & 19.0 \\
\hline $4: 96$ & $20: 480$ & 0.8 & 0.7334 & 0.367 & 19.2 \\
\hline $3: 97$ & $15: 485$ & 0.6 & 0.5334 & 0.267 & 19.4 \\
\hline $1: 99$ & $5: 495$ & 0.2 & 0.1334 & 0.067 & 19.8 \\
\hline
\end{tabular}

tions.

\section{Experimental}

The inhibitor standard solution was prepared using radioactive $\mathrm{Cr}-51$ (half life $=22.8$ days) in $\mathrm{Na}_{2} \mathrm{CrO}_{4}$ solution of specific activity $119.3 \mathrm{mc} / \mathrm{mg}$. $15 \mathrm{cc}$ of this standard active solution was used in each case, which contained $66.66 \mu \mathrm{g}$ of active $\mathrm{Na}_{2} \mathrm{CrO}_{4}$. The balance of chromate required was made up by inactive $\mathrm{Na}_{2} \mathrm{CrO}_{4}$ solution. Thus inactive $\mathrm{Na}_{2} \mathrm{CrO}_{4}$ was used in conjunction with radioactive $\mathrm{Na}_{2} \mathrm{CrO}_{4}$ for the first time, to adjust the desired activity for maximum sensitivity in counting, instead of the standard practice of diluting the active solution.

Total amount of chromate and borate in all experimental solutions was fixed at $500 \mathrm{ppm}$ and the ratio of chromate and borate (by weight) was varied between $90: 10$ and $1: 99$ in fourteen discreet steps. Borate and distilled water were added to make $40 \mathrm{cc}$ of experimental solutions. Table 1 shows the compositions of various experimental solutions. The standards were made by putting $0.05 \mathrm{cc}$ of standard active solution onto the blank sample, drying and counting by a Geiger-Muller counter. Count rates on the standards and specimens were corrected for the background and the finite resolving time of the counting system. The corrected count rates were found to be proportional to their relative concentrations, indicating the absence of counting errors due to absorption of radiations.

The specimens having size of $1.5 \mathrm{~cm} \times 1.5 \mathrm{~cm}$ were cut from cold rolled mild steel, polished, degreased with benzene and fitted onto the glass tube. They were exposed to air for a predetermined time of $35 \mathrm{~min}$ before immersion so that the air grown oxide film on the surface of the specimen remained constant. The specimens were immersed in the experimental solutions, saturated with purified nitrogen in the experimental set-up designed, fabricated at National Metallurgical Laboratory, Jamshedpur, India and described earlier. ${ }^{17-21)}$ The oxidation process was thus controlled solely by the inhibitor. All the immersion experiments were conducted at room
Table 2. pH values of solutions before and after exposure (303 K)

\begin{tabular}{|c|c|c|c|c|}
\hline Sl. No. & $\begin{array}{c}\text { Chromate: } \\
\text { Borate } \\
\text { (By wt.) }\end{array}$ & $\begin{array}{l}\text { Time of } \\
\text { exposure } \\
\text { (min) }\end{array}$ & $\begin{array}{c}\mathrm{pH} \\
\text { before } \\
\text { exposure }\end{array}$ & $\begin{array}{c}\mathrm{pH} \\
\text { after } \\
\text { exposure }\end{array}$ \\
\hline 1 & $90: 10$ & 240 & 7.96 & 8.05 \\
\hline 2 & $80: 20$ & 240 & 7.88 & 8.04 \\
\hline 3 & $70: 30$ & 240 & 7.88 & 8.08 \\
\hline 4 & $60: 40$ & 240 & 7.80 & 7.98 \\
\hline 5 & $50: 50$ & 240 & 7.75 & 7.88 \\
\hline 6 & $40: 60$ & 240 & 7.69 & 7.80 \\
\hline 7 & $30: 70$ & 240 & 7.62 & 7.76 \\
\hline 8 & $20: 80$ & 240 & 7.51 & 7.63 \\
\hline 9 & $10: 90$ & 240 & 7.37 & 7.58 \\
\hline 10 & $5: 95$ & 240 & 7.18 & 7.60 \\
\hline 11 & $4: 96$ & 240 & 7.23 & 7.56 \\
\hline 12 & $3: 97$ & 240 & 7.14 & 7.52 \\
\hline 13 & $2: 98$ & 240 & 7.07 & 7.48 \\
\hline 14 & $1: 99$ & 240 & 6.80 & 7.62 \\
\hline 15 & $60: 40$ & 10 & 7.80 & 7.85 \\
\hline 16 & $60: 40$ & 20 & 7.82 & 7.85 \\
\hline 17 & $60: 40$ & 30 & 7.84 & 7.98 \\
\hline 18 & $60: 40$ & 60 & 7.82 & 7.98 \\
\hline 19 & $60: 40$ & 120 & 7.82 & 7.98 \\
\hline 20 & $60: 40$ & 180 & 7.85 & 8.02 \\
\hline 21 & $60: 40$ & 300 & 7.85 & 8.08 \\
\hline 22 & $60: 40$ & 360 & 7.85 & 8.08 \\
\hline 23 & $50: 50$ & 360 & 7.81 & 8.03 \\
\hline
\end{tabular}

temperature $(303 \mathrm{~K})$. Generally an immersion time of up to $4 \mathrm{~h}$ was used for all compositions of the chromate and borate mixtures. However, at the composition of $60: 40$, the effect of immersion time on $\mathrm{Cr}$ content in the film was studied by varying it from $10 \mathrm{~min}$ to $6 \mathrm{~h}$. The open circuit potential of the specimens was measured constantly against a saturated calomel electrode using Luggin capillary and a d.c. micro voltmeter. After immersion, the specimens were washed with distilled water and acetone, dried, and subjected to counting with the Geiger-Muller counter for $10 \mathrm{~min}$. Comparing with standards, the weights of active chromium on the surfaces of specimens were determined. The proportional weights of inactive $\mathrm{Cr}$ were calculated from the relative concentrations of active and inactive $\mathrm{Cr}$ in the solution. The 
total weight of $\mathrm{Cr}$ on the surface was divided by the surface area of each specimen. The $\mathrm{pH}$ of the experimental solutions were measured before and after each exposure as shown in Table 2. The exposed specimens were examined by an optical microscope for the appearance of rust spots/pits.

\section{Results and Observations}

Table 2 shows that there is a marginal increase in $\mathrm{pH}$ after the exposure. The $\mathrm{Cr}$ composition in the inhibitor film on specimen surface increases as borate concentration in the experimental solution is increased up to $40 \%$. Figure 1 shows that after a maximum at this value, the amount of $\mathrm{Cr}$ in the film decreases as borate is increased further up to $95 \%$. Figure 2 shows that at the chromate-

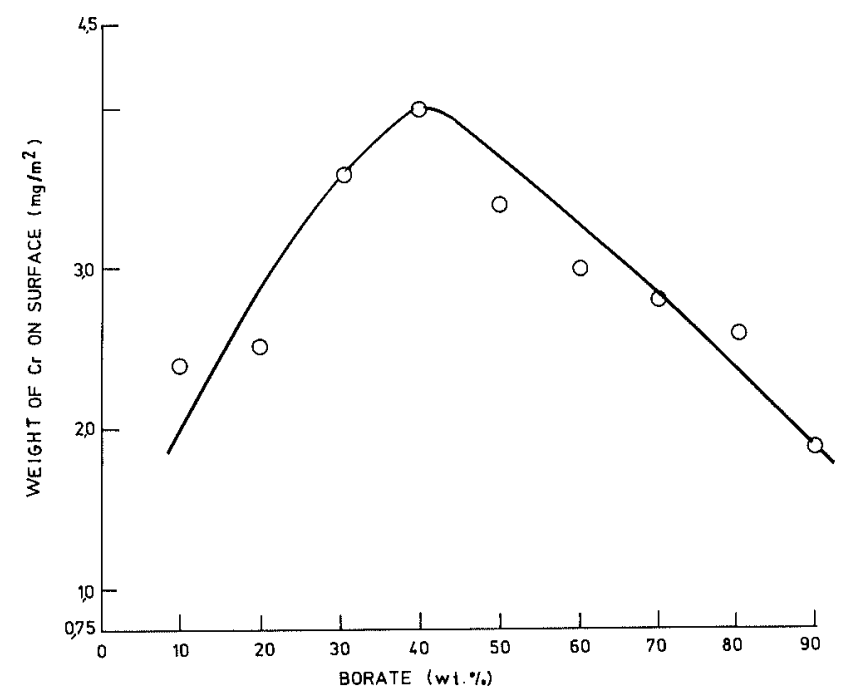

Fig. 1. Effect of borate content on $\mathrm{Cr}$ content picked up by mild steel, immersion period $=4 \mathrm{~h}$, specimens preexposed to air for $35 \mathrm{~min}$.

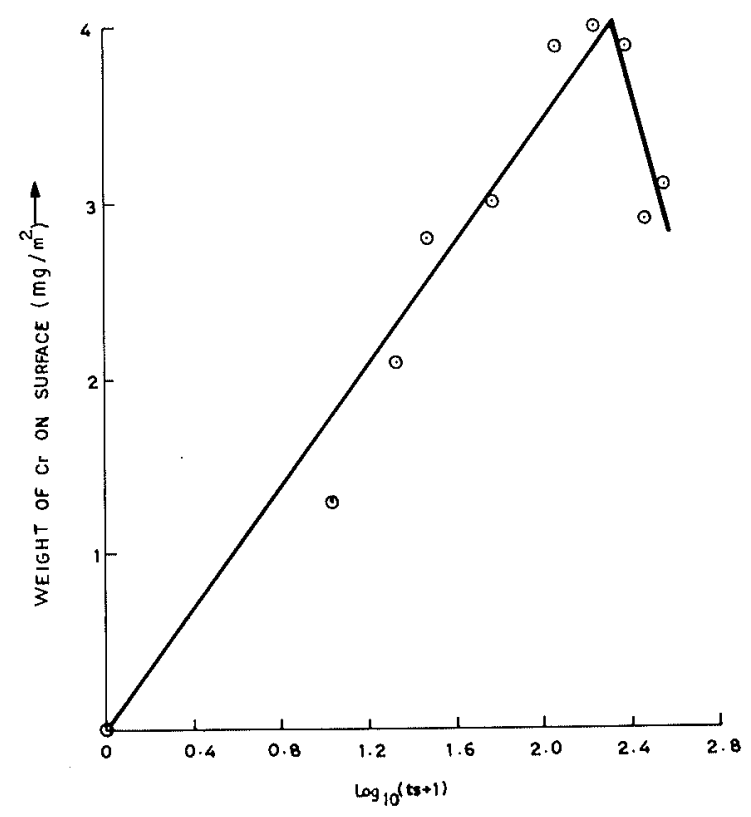

( $t 3=$ TIME OF IMMERSION IN MINUTES )

Fig. 2. Cr content picked up by mild steel in chromate-borate mixture (ratio $60: 40$ ) at $303 \mathrm{~K}$ saturated with $\mathrm{N} 2$, specimens pre-exposed to air for $35 \mathrm{~min}$. borate ratio of $60: 40$, the $\mathrm{Cr}$ content picked up in the film studied as a function of time shows a steady logarithmic growth in the $\mathrm{Cr}$ content in the film from 1.0 to a maximum of $4.0 \mathrm{mg} / \mathrm{m}^{2}$ in $2-4 \mathrm{~h}$, after which it decreases.

Figures 3 to $\mathbf{5}$ display that the open circuit potential shifts towards less noble values initially up to one hour, and later shifts towards more noble values. This trend indicates the predominance of anodic polarization (after one hour) up to chromate-borate ratio of 5:95. On

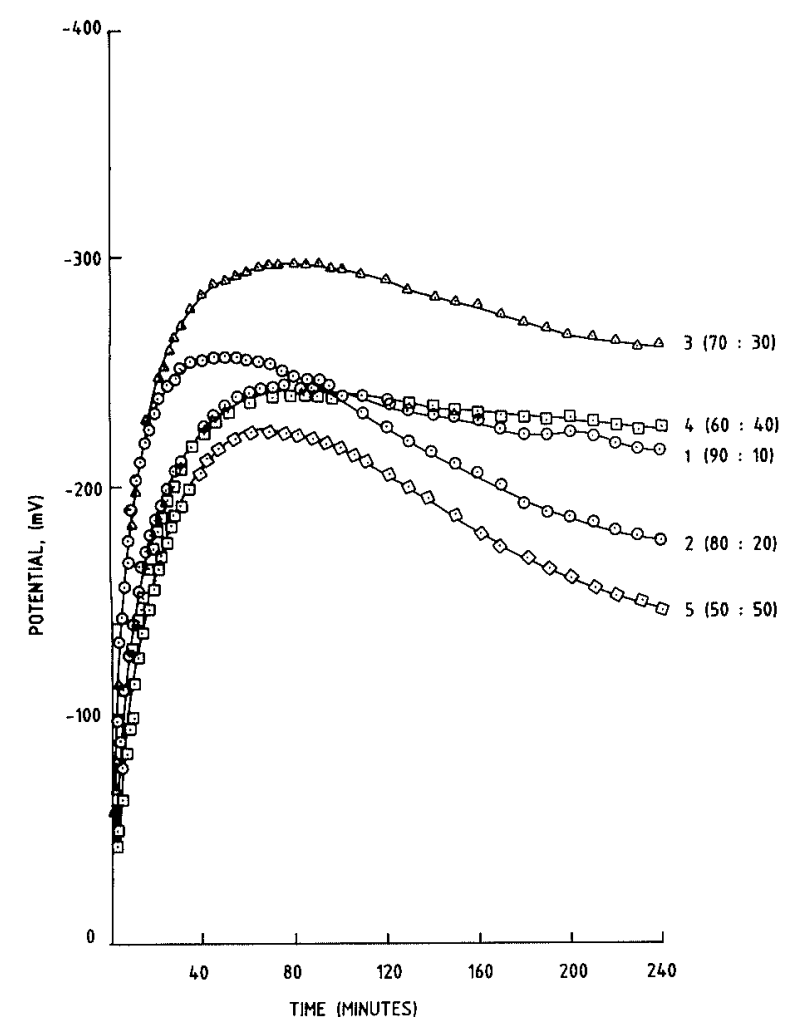

Fig. 3. Open circuit potential change of cold rolled mild steel with time, immersed in solutions containing chromate and borate in ratios (by wt.) as shown, at $303 \mathrm{~K}$.

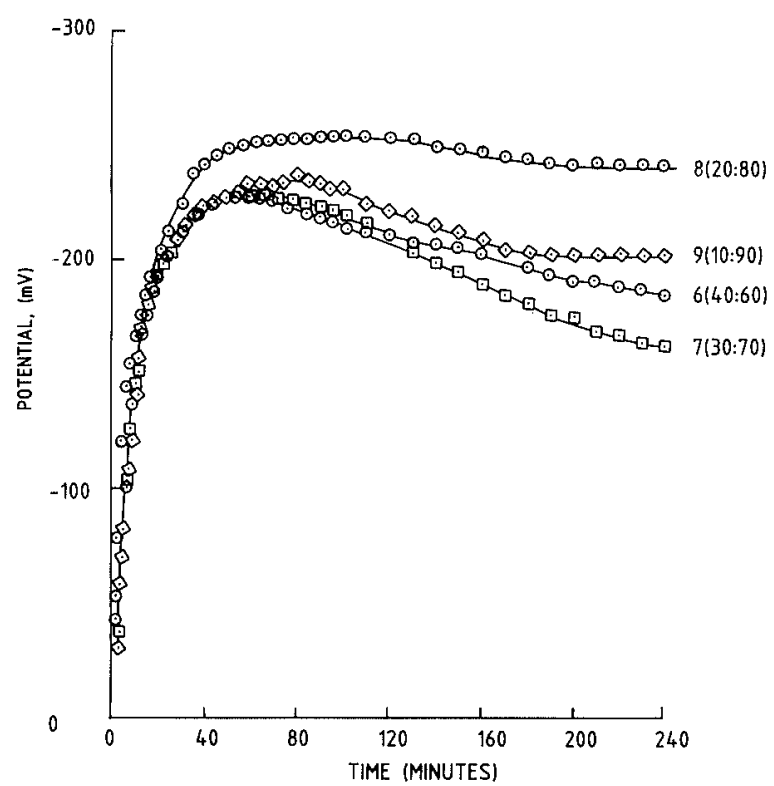

Fig. 4. Open circuit potential change of cold rolled mild steel with time, immersed in solutions containing chromate and borate in ratios (by wt.) as shown, at $303 \mathrm{~K}$. 


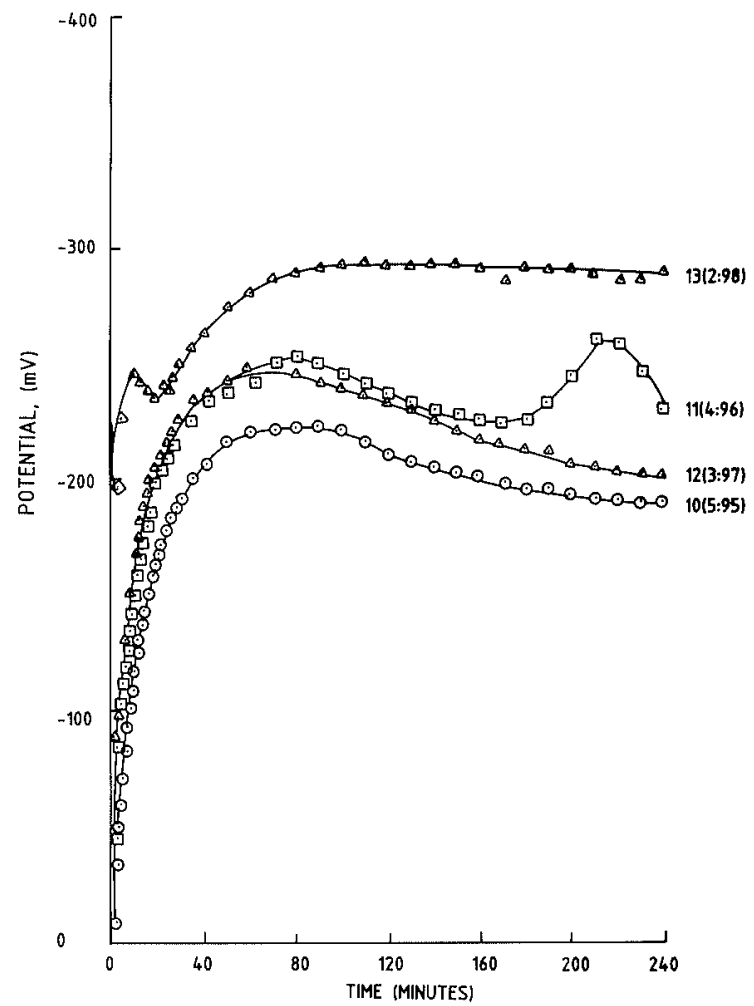

Fig. 5. Open circuit potential change of cold rolled mild steel with time immersed in solutions containing chromate and borate in ratios (by wt.) as shown, at $303 \mathrm{~K}$

increasing borate to $98 \%$, the potential decreases and then stays constant. Some pits were detected from the specimen in the $98 \%$ borate solution. In the other cases no rust spots were detected. The specimen containing the maximum $\mathrm{Cr}$ in the film ( $40 \%$ borate) had bright and clean surface, showing protection at $303 \mathrm{~K}$ at least up to $6 \mathrm{~h}$.

\section{Discussion}

Borate was added to chromate inhibitor to partially replace it. Borate acts as a buffer in the solution and its presence is useful since slight change in $\mathrm{pH}$ is adjusted automatically. The combination of chromate and borate as an inhibitor has not been tried industrially. The cost of this inhibitor would be much less than that of the inhibitor containing phosphate and borate being used at present. By reducing the chromate content in the inhibitor, the toxic effect of chromate is also reduced. Borate substituted up to $97 \%$ in chromate is found to protect mild steel at $303 \mathrm{~K}$ at least up to $6 \mathrm{~h}$, as the surface remained clean and bright and no rust spots were detected.

Another interesting aspect of the study is that, by actually reducing chromate in the inhibitor solution from 100 to $60 \%$, we are able to increase the chromate in the protective film depositing on the mild steel surface from 2.0 to $4.0 \mathrm{mg} / \mathrm{m}^{2}$ in $2-4 \mathrm{~h}$ immersion time. It means that, with less $\mathrm{Cr}$ in the inhibitor solution, $\mathrm{Cr}$ deposition on the specimen surface has doubled in $4 \mathrm{~h}$. This shows the synergistic effect of chromate and borate together as compared to that of chromate alone. This is in line with the earlier observations ${ }^{22)}$ that even small additions of oxidative inhibitors to borate retard corrosion, suppressing it completely at concentrations which themselves intensify corrosion. Also, it was noticed that the required concentration of oxidative inhibitor must be lower as that of the non oxidative inhibitor is higher. Mixtures were found to shift the steel potential to passive state at much lower concentrations than either alone.

The open circuit potential is the resultant of anodic and cathodic reactions that exists upon the surface of a metal. The phenomenon causes transport of electron through the metal from anode to cathode. Due to the current flow polarization potential is developed. When cathodic reaction is stronger, strong polarization at anodes takes place and the corrosion is anodically controlled. The trend of the open circuit potential in this study is that of initial sharp decrease to more negative values followed by slight increase after one hour of immersion time, resulting in anodic polarization on the surface. This remains valid up to the chromate borate ratio of $3: 97$. This is equivalent to introduction of a high resistance in the anodic reaction, decreasing the anodic current. The protection occurs when anodic current decreases since the rate of corrosion as measured by weight loss/second is proportional to total action current (Faraday's law). The protection therefore occurs when anodic current decreases.

In order to explain the mechanism of $\mathrm{Cr}$ pickup in the film in these cases, the following stoichiometric reaction may be assumed to progress at mild steel/inhibitor solution interface during immersion at $303 \mathrm{~K}$ :

$$
2 \mathrm{Fe}+2 \mathrm{CrO}_{4}^{2-}+2 \mathrm{H}_{2} \mathrm{O}=\mathrm{Fe}_{2} \mathrm{O}_{3}+\mathrm{Cr}_{2} \mathrm{O}_{3}+4\left(\mathrm{OH}^{-}\right)
$$

According to this equation, the oxide film containing $\mathrm{Fe}_{2} \mathrm{O}_{3}$, and $\mathrm{Cr}_{2} \mathrm{O}_{3}$ forms on mild steel surface ${ }^{24)}$ and grows logarithmically with time, ${ }^{23)}$ indicating that electron transfer through the film is the rate controlling step. Under this condition, sufficient current could be generated to polarise the local anodes. In the case of chromates alone, there is a marked predominance of anodic polarization as shown in our earlier work (Fig. $\left.5^{2)}\right)$. In chromate + borate solution, the open circuit potential of mild steel shows predominance of anodic polarization after $1 \mathrm{~h}$ of immersion up to borate level of $97 \%$. The mechanism of growth of $\mathrm{Cr}$ content in the film is represented again by Eq. (1). Accordingly, the film grows logarithmically with time indicating that electron transfer through the film is the rate controlling step. The presence of borate has decreased the level of anodic polarization, as shown by shifting of the potential curves towards cathodic values. Thus like chromate, the chromate+borate inhibitor also protects mild steel anodically.

\section{Conclusions}

Chromate replaced by borate up to $97 \%$ is found to protect mild steel in aqueous solutions at $303 \mathrm{~K}$ at least up to $6 \mathrm{~h}$. The adhesion of the protective film to the surface is good. The open circuit potential shows the 
predominance of anodic polarization at a borate content up to $97 \%$.

The chromate content in the protective film increases when chromate is reduced from 100 to $60 \%$. At this particular combination of inhibitor, the $\mathrm{Cr}$ content in the film is maximum in 2-4 h and is double of that formed with $100 \%$ chromate. This shows the synergistic effect of the combination of chromate and borate which also reduces the toxic effect of using chromate alone.

\section{Acknowledgments}

The author wishes to thank Dr. Inder Singh, Scientist, National Metallurgical Laboratory for help in planning the experiments and ex-colleague $\mathrm{Mr}$. K. D. Maji for initial help during experimentation. Thanks are also due to Prof. P. Ramachandra Rao, Director, NML for permission to publish this paper.

\section{REFERENCES}

1) E. McCafferty: Corros. Sci., 29 (1989), 391.

2) K. D. Maji, Inder Singh and R. Kumar: Trans. Indian Inst. Met., 29 (1976), 374.

3) G. B. Hatch: Corrosion Inhibitors, ed. by C. C. Nathan, NACE Publ., (1973), 126.

4) Lu Zhu, Zhang Shi-Zhong et al.: Int. Cong. on Met. Corrosion, National Research Council Canada, 1 (1984), 338.

5) J. Golden and J. E. O. Mayne: Br. Corros. J., 13 (1978), 45.
6) W. Meisel, E. Mohs, H. J. Guttman and P. Gulleich: Corros. Sci., 23 (1983), 465.

7) J. Schreifels, P. Labine, R. Gailey, S. Goewert, M. O'Brein and S. Jost: Corrosion, 45 (1989), 420.

8) F. H. Al-Hajjar and W. T. Riad: Br. Corros. J., 25 (1990), 119.

9) O. Hollandar, G. E. Geiyer and W. C. Ehrhardt: Corrosion 82, Paper No. 226, Houston, NACE, (1982).

10) H. L. Kahler and C. George: Corrosion, 6 (1950), 331.

11) R. S. Glass: Corrosion, 41 (1985), 89.

12) P. A. Burda: Asia Corrosion Conf., Singapore, Inst. for Int. Res., (1988), 13.1.

13) M. S. Vukasovich: Mater. Perform., 29 (1990), 48.

14) H. C. Schuldener and S. Sussman: Corr. Source Book, ed. by S. K. Coburn, Pub. ASM 67 (1984).

15) A. Neufeld, J. Spiteri-Gonzi and C. Moore: Ind. Corros., 5(1987), 6.

16) D. M. Cartledge: Br. Corros. J., 1 (1966), 293.

17) Aruna Bahadur: Corros. Rev., 7 (1987), 95.

18) K. D. Maji, Aruna Bahadur and Inder Singh: Proc. of 5th Europe Symp. on Corr. Inhibitors, Ferrara, (Italy), 593 (1980).

19) Aruna Bahadur: Corros. Rev., 10 (1992), No. 1-2, 155.

20) Aruna Bahadur: Corros. Rev., 11 (1993), No. 1-2, 105.

21) Aruna Bahadur: Mater. Trans. JIM, 34 (1993), No. 12, 1191.

22) I. L. Rozenfeld, L. V. Frolova and V. N. Tavadze: Prot. Met., 16 (1980), 103

23) O. Kubaschewski and D. M. Brasher: Trans. Faraday, Soc., 55 (1959), 1200.

24) A. D. Mercer, I. R. Jenkins and J. E. Rhodes-Brown: Br. Corros. $J ., 3$ (1968), 136. 